Lydia Koetz ${ }^{1}$

Claudete Rempel ${ }^{1}$

Eduardo Périco ${ }^{1}$
${ }^{1}$ Centro Universitário Univates. Rua Avelino Tallini 171, Universitário. 95900-000 Lajeado RS. lkoetz@gmail.com

\section{Qualidade de vida de professores de Instituições de Ensino Superior Comunitárias do Rio Grande do Sul}

\author{
Quality of life of professors of higher education community \\ institutions in the state of Rio Grande do Sul, Brazil
}

\begin{abstract}
Quality of life is the subjects'perception of their status in society, permeated by culture, values and everyday life and with a view to their life goals and expectations as well as the ways of thinking about life. The study investigated the quality of life of professors of higher education community institutions that have been in operation for more than 40 years and have more than ten thousand students in the State of Rio Grande do Sul. The research, with a qualitative-quantitative cross-sectional approach was conducted in August and September 2011 using a professional profile questionnaire and the WHOQQL-BREF questionnaire, in which 203 professors participated, namely $17 \%$ of all the professors in the three institutions analyzed. When the quality of life rate was analyzed according to the teachers' education, the 22 specialists scored highest in the psychological field $(72.1 \pm 3.1)$ and lowest in the social field $(69.3 \pm 4.4)$. Among the 125 masters and the 43 PhD's, the highest scores were found in the physical domain $(74.8 \pm 1.3$ and $75.7 \pm$ 2.1 , respectively) and the lowest in the environmental field ( $69.4 \pm 1.0$ and $70.8 \pm 1.8$ ). The conclusion reached was that the quality of life of the professors was considered good in the fields analyzed. There was no significant statistical difference among them.
\end{abstract}

Key words Quality of life, Occupational health, Environment
Resumo Qualidade de vida é a percepção dos sujeitos sobre sua posição perante a sociedade, permeada por sua cultura, valores e cotidiano e com vistas a seu objetivo e expectativas de vida e as formas de pensar sobre sua vida. O estudo investigou a qualidade de vida de docentes de instituições de ensino superior comunitárias não confessionais, com mais de 40 anos de atuação e com mais de dez mil alunos no Rio Grande do Sul. A pesquisa, com perfil quali-quantitativo e de corte transversal, ocorreu em agosto e setembro de 2011, através de um questionário de perfil profissional e do questionário WHOQOL-bref. Participaram 203 professores, perfazendo $17 \%$ do total de docentes das três instituições analisadas. Quando analisado o indice de qualidade de vida de acordo com a titulação dos docentes, os 22 especialistas apresentam o maior escore no domínio psicológico $(72,1 \pm 3,1)$ e o menor no domínio social $(69,3$ $\pm 4,4)$, entre os 125 mestres $e$ os 43 doutores os maiores escores foram no dominio físico $(74,8 \pm$ 1,3 e 75,7 $\pm 2,1$ respectivamente) e os menores no domínio ambiental $(69,4 \pm 1,0$ e 70,8 $\pm 1,8$ respectivamente). Conclui-se que o indice de qualidade de vida dos docentes foi enquadrado como bom em todos os domínios analisados e sem diferença estatística significativa entre eles.

Palavras-chave Qualidade de vida, Saúde do trabalhador, Ambiente 


\section{Introdução}

Universidades Comunitárias, segundo o Projeto de Lei das Instituições Comunitárias brasileiras, PL 7639/2010, são instituições de educação superior, privadas, com patrimônio pertencente à sociedade civil e sem fins lucrativos ${ }^{1}$. A Associação Brasileira de Universidades Comunitárias, ABRUC, afirma que as universidades comunitárias atendem $27 \%$ dos estudantes brasileiros e somam 437 instituições de ensino superior no país ${ }^{2}$.

Ao todo, segundo o censo da educação de 2009, realizado pelo Instituto Nacional de Estudos e Pesquisa Educacional Anísio Teixeira (INEP), o Rio Grande do Sul conta com 16.226 professores universitários. Destes, 9.146 estão nas instituições comunitárias. Pensar a qualidade de vida destes profissionais, que são os responsáveis pela formação de novos atores sociais, torna-se relevante uma vez que estes estão em contato direto com o público e são grandes formadores de opinião. Por qualidade de vida, no presente artigo, utiliza-se do conceito criado pela Organização Mundial de Saúde (OMS) ${ }^{3}$ entendida como a capacidade do sujeito de perceber sua posição na vida, através da cultura e valores que permeiam seu cotidiano, abordando seus objetivos, expectativas, suas formas de pensar e as preocupações que permeiam sua vida ${ }^{4}$. Neste sentido, a indagação em que se baseia o presente estudo é: como os docentes percebem sua qualidade de vida e quais os fatores que são determinantes para este?

Saúde, segundo a Lei 8080/90, tem como fatores determinantes e condicionantes a garantia de acesso à moradia, alimentação, saneamento, trabalho, renda, transporte, entre outros ${ }^{5}$.

O presente artigo tem como tema a qualidade de vida abordando a percepções dos sujeitos sobre sua posição na sociedade, permeada por sua cultura, valores e cotidiano e com vistas a seu objetivo e expectativas de vida, bem como as formas de pensar sobre sua vida de docentes de instituições de ensino superior comunitárias não confessionais do Rio Grande do Sul, identificada através da aplicação do questionário elaborado pelo World Health Organization Quality of Life - bref (WHOQOL-bref) ${ }^{4}$.

Docentes universitários são os responsáveis pela formação de profissionais de diferentes áreas do conhecimento. Tendo em vista a responsabilidade, a carga horária, o ambiente e a demanda de trabalho, o presente estudo levanta como hipótese que os fatores limitantes que influencia- rão na qualidade de vida serão limitação de tempo para realização de atividades de lazer, bem como que fatores relacionados ao acesso aos serviços de saúde e transporte não serão indicados como limitantes.

Diante do exposto, o presente estudo traz como objetivo geral identificar a qualidade de vida de docentes de instituições de ensino superior comunitárias não confessionais do Rio Grande do Sul quanto aos domínios físico, psicológico, social e ambiental.

Os objetivos específicos referem-se a conhecer os determinantes que influenciam nas percepções dos docentes sobre qualidade de vida através da análise dos domínios do WHOQOLbref e caracterizar o índice de qualidade de vida indicado através da análise do questionário.

O estudo realizou-se com professores de três instituições de ensino superior comunitária não confessional com mais de dez mil alunos e com atividades de ensino superior a 40 anos. Foram convidados a participar da pesquisa 1200 professores. O estudo foi apreciado e aprovado pelo Comitê de Ética em Pesquisa do Centro Universitário Univates garantido que o estudo cumpre as "diretrizes e normas que regulamentam pesquisas com seres humanos", editadas pelo Conselho Nacional de Saúde e aprovado pelo comitê de ética do Centro Universitário da Univates.

Em relação à sua classificação, o estudo enquadra-se como de campo, exploratório, qualiquantitativo e transversal.

A coleta de dados do estudo ocorreu em agosto de 2011. Os professores receberam os questionários impressos (WHOQOL-bref e questionário de perfil profissional) em conjunto com o Termo de Consentimento Livre e Esclarecido (TCLE) e uma correspondência eletrônica de apresentação da pesquisa e a forma de preenchimento dos questionários.

O questionário WHOQOL-bref é autoaplicável, de fácil compreensão e o docente foi orientado a marcar a questão na qual identifica sua qualidade de vida. Em conjunto com o questionário de qualidade de vida, foi encaminhado o de perfil profissional, composto por questões abertas e fechadas, que indagaram sobre questões a respeito do ambiente de trabalho, dados sociais e atividades de lazer.

O questionário WHOQOL-bref é composto por 26 questões, sendo duas de domínio geral e 24 referentes aos domínios avaliados no questionário que contém 100 questões, os domínios investigados no questionário abreviado referem-se a relações sociais, aspectos físicos, psicológicos e 
ambientais. Os dados que compuseram o questionário abreviado foram extraídos de testes realizados em campo por dezoito países diferentes.

O questionário foi traduzido para o português pela Universidade Federal do Rio Grande do Sul, em 1998, coordenado pelo Dr. Marcelo Fleck. O questionário de qualidade de vida WHOQOL teve sua elaboração iniciada em 1991, com objetivo de desenvolver uma ferramenta que pudesse ser aplicada em diferentes culturas através do mesmo instrumento. Trata-se de um questionário autoaplicável que aborda a percepção dos sujeitos em seu contexto, sua cultura e seus valores sobre sua qualidade de vida ${ }^{3}$. Três itens foram apontados como fundamentais para se referir à qualidade de vida: subjetividade, multidimensionalidade, presença de dimensões positivas e negativas como, por exemplo, capacidade de locomover-se e dor respectivamente. Neste sentido, a Organização Mundial de Saúde conceituou qualidade de vida como "a percepção do indivíduo de sua posição na vida no contexto da cultura e sistema de valores nos quais ele vive e em relação aos seus objetivos, expectativas, padrões e preocupações"4.

Portanto, pretendeu-se obter com o presente estudo o escore de qualidade de vida dos docentes das universidades comunitárias não confessionais do Rio Grande do Sul para suscitar a reflexão acerca das percepções dos docentes e para identificar os domínios que determinam a qualidade de vida destes atores.

Os questionários foram deixados nas secretarias onde estão alocados os escaninhos dos professores e, passado o período de uma semana, os mesmos foram coletados e tabulados no programa Microsoft Office Excel. Os mesmos foram analisados conforme sintaxe prevista pelo grupo de estudos que realizou a tradução do documento. A análise estatística foi realizada utilizando estatística descritiva e inferencial. Para análise estatística, foi utilizado o software BIOESTAT 5.0 $0^{6}$ As variáveis quantitativas foram descritas através de média e erro padrão e as variáveis qualitativas através de frequência absoluta e relativa. Os resultados estão apresentados em tabelas e gráficos. O teste t de Student, ANOVA (teste de Tukey), Kruskal-Wallis, correlação de Pearson e correlação de Spearman foram utilizados para comparação dos grupos. O nível de significância adotado foi de $5 \%$, sendo considerados significativos valores de $\mathrm{p}<0,05$.

As respostas dos professores referentes ao o que é qualidade de vida e quais as atividades de lazer realizadas pelos professores foram catego- rizadas e analisadas conforme análise de conteúdo de Bardin ${ }^{7}$, com a identificação de categorias e subcategorias emergentes das falas da população do estudo. Bardin ${ }^{7}$ define a análise de conteúdo como técnicas de análise de comunicações visando obter instrumentos sistemáticos e objetivos de descrição do conteúdo das mensagens, e indicadores que irão permitir aprofundar os conhecimentos relativos às mensagens. Para melhor compreensão dos escores de qualidade de vida dos docentes, a escala foi divida em cinco itens, seguindo a proposta de $\operatorname{Padrão}^{8}$ que apontam a qualidade de vida muito ruim (0-20); ruim (21-40); nem ruim nem boa (41-60); boa (61$80)$ e muito boa (80-100).

Ao todo, foram enviados 1200 questionários aos professores de graduação das instituições de ensino, destes obteve-se a resposta de 203 professores ( $17 \%$ de retorno), acima da média de $15 \%$ para esse tipo de levantamento, conforme Malhotra9. A amostra foi composta por 64 homens (33\%) e 133 mulheres (67\%).

Em 2009, o Sindicato de Professores do Ensino Privado do Rio Grande do Sul, o SINPRORS, divulgou o estudo "Condições de trabalho e saúde do professor nas instituições de ensino privado do Rio Grande do Sul”, neste, os dados encontrados em relação ao gênero dos professores entrevistados foi semelhante aos dados apresentados nesta dissertação. Segundo o estudo, $69 \%$ dos entrevistados são do sexo feminino, enquanto o restante (31\%) é compreendido por homens ${ }^{10}$. Belluci ${ }^{11}$, em seu trabalho, que aborda a feminização do trabalho de professora no Brasil, segundo a ótica do Marxismo, afirma que as mulheres escolhem sua profissão de forma estratégica para se manterem no mercado de trabalho, desta forma recorrem a algumas profissões que se remetem, em sua essência, a subordinação ou ao papel de cuidadoras, dentre estas possibilidades destacam-se profissões da área da saúde, doméstica ou professora. A autora afirma que nestes espaços há discriminação por gênero, ainda que velada. Apesar da carga horária de trabalho ser semelhante entre homens e mulheres, Belluci ${ }^{11}$ afirma ainda que as mulheres assumem jornadas de trabalho duplas, uma vez que estas são responsáveis pela manutenção de suas residências e de suas famílias.

A idade dos professores variou de 26 a 64 anos, sendo a média de 42 anos $( \pm 0,7)$. Os entrevistados atuam como docentes, em média, há 13 anos $( \pm 0,6)$. Dado este semelhante ao encontrado na pesquisa realizada pelo SINPRO/RS cuja maior concentração dos professores foi na faixa 
etária entre 41 e 50 anos, e destaca-se que a maior parte destes professores referia idade superior a 36 anos $^{10}$.

Dos entrevistados na pesquisa do sindicato, $86 \%$ atuam como docentes há mais de seis anos e $50 \%$ atuam a mais de 16 anos na profissão ${ }^{10}$. A presente pesquisa aponta que aproximadamente $7 \%$ dos entrevistados atuam há menos de um ano, $11,8 \%$ estão atuando como professores nos últimos dois a cinco anos, $26,5 \%$ dos entrevistados estão trabalhando na área da docência entre seis a dez anos, pouco mais de $20 \%$ atuam como professores entre 16 a 20 anos, $12,8 \%$ dos professores atuam no campo do ensino de 21 a 25 anos, aproximadamente $6 \%$ atuam na área entre $26 \mathrm{e}$ 30 anos, cerca de $1 \%$ há 31 a 35 anos e 2,5\% atuam há mais de 40 anos como professores universitários. A maior parte dos entrevistados atua entre seis e 15 anos, as duas categorias juntas somam mais de $46 \%$ do total de entrevistados.

Os significados em torno da profissão se estruturam principalmente no reconhecimento social. Ser professor está relacionado a participar da independência das pessoas, a torná-las mais livres, menos dependentes econômica, política e socialmente, que vai muito além do ato de ensinar. A forma de contextualizar a história, cultura e a sociedade é que define o papel do docente. $\mathrm{O}$ olhar tridimensional, composto pelo individualizado (ou seja, ver a especificidade do aluno), o contextual (considerando o espaço e tempo em que atua) e a capacidade de contextualizar a história e a ação política. Assim, o professor é um profissional que transmite seus conhecimentos desde a relativização do conteúdo, pelas situa- ções que vivencia e pelo contexto no qual está inserido $^{12}$

A carga horária semanal média dos professores é de 32,5 horas $( \pm 0,9)$, destaca-se que $48,3 \%$ dos professores afirmam que sua carga horária é de 40 horas semanais, seis professores afirmaram que sua carga horária é maior do que 45 horas semanais, um deles chegando a 64 horas semanais. Estes dados demonstram o quanto é necessário pensar em ações de prevenção e promoção de saúde para os professores, uma vez que a atuação dos professores em sala de aula demanda permanecer em ortostase (em pé) por longos períodos e uma atividade intelectual que necessita de extrema atenção e horas de preparo de aulas e de correção de trabalho.

Os questionamentos sobre qualidade de vida conferem um escore para quatro domínios: físico, psicológico, social e ambiental. Para melhor compreensão das pontuações, a escala foi divida em cinco itens, seguindo a proposta de Padrão ${ }^{8}$. O percentual de indivíduos de acordo com os escores, por domínio, pode ser observado no Gráfico 1.

A média das respostas aponta para uma boa qualidade de vida em todos os domínios analisados, sendo maior no domínio físico e menor no domínio ambiental: domínio físico $(74,5 \pm 1,0)$, domínio psicológico $(72,7 \pm 0,9)$, domínio social $(71,3 \pm 1,2)$, domínio ambiental $(69,7 \pm 0,8)$.

O domínio físico foi determinado pela percepção dos professores frente a sua dor, a necessidade de tratamento médico, como os entrevistados percebem a sua energia para as atividades do cotidiano, a capacidade de locomoverem-se,

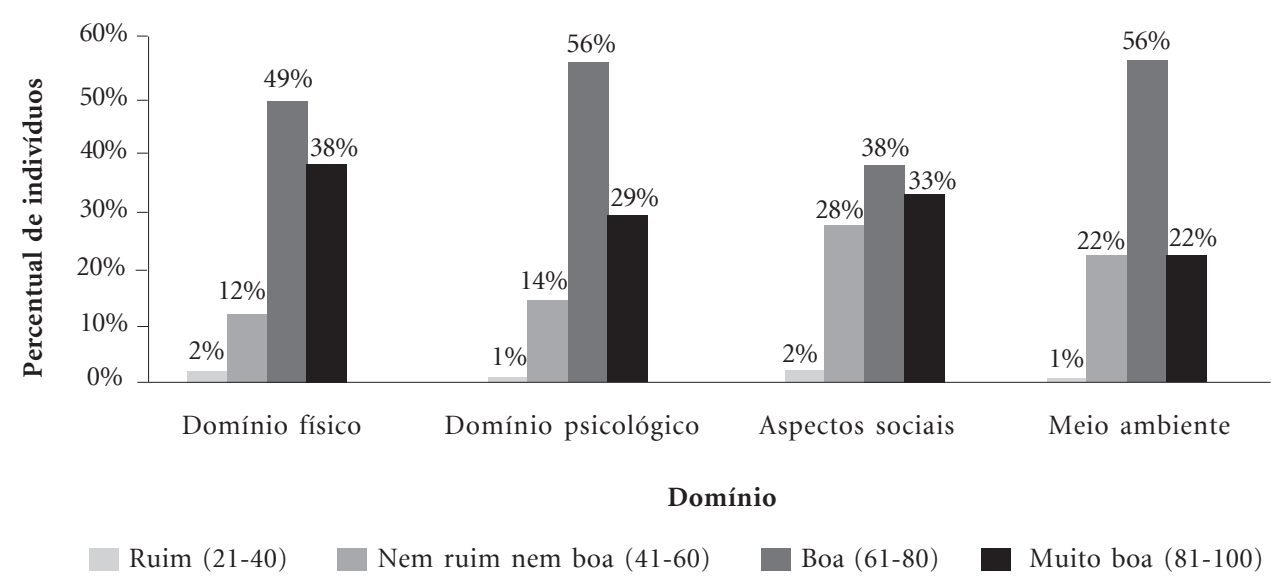

Gráfico 1. Percentual de distribuição dos escores de qualidade de vida de acordo com os domínios analisados. 
a satisfação com o sono, de desenvolver as atividades diárias e com a capacidade de realizar seu trabalho. A média das pontuações aponta que um escore de $74,4( \pm 5,3)$, ou seja, para uma qualidade de vida considerada boa. A centralidade do trabalho é bastante aparente neste item, pois a capacidade física significa conseguir desempenhar o trabalho, manter as atividades necessárias para prover o sustento dos familiares ${ }^{13}$. A centralidade do trabalho na sociedade esta em uma sociedade que se estrutura pela perspectiva deste, como forma de criticar o economicismo, que utiliza as relações sociais como um instrumento, onde a vida social tem como objetivo o consumismo e a mercantilização generalizada, gerando a destruição ambiental ocasionada pela exploração desenfreada. Em suma, o trabalho assume a perspectiva de extrema importância na vida das pessoas ${ }^{13}$.

Para identificação do escore de qualidade de vida em relação aos aspectos psicológicos os professores foram indagados se, na sua percepção, aproveitam a vida, se esta tem sentido e se o entrevistado consegue se concentrar, além de indagar a aceitação em relação à aparência física, a frequência de sentimentos como desespero e ansiedade e se o entrevistado sente-se satisfeito consigo mesmo.

A qualidade de vida no que tange ao domínio social aponta para um escore de $71,3( \pm 1,2)$, para quantificá-la os professores foram estimulados a refletir sobre a relação com os colegas, a vida sexual e com o apoio que recebe dos amigos.

Para identificar o escore de qualidade de vida no que tange ao ambiente, os professores foram questionados em relação à sensação de segurança, se o ambiente físico (poluição, clima, barulho) pode ser considerado saudável, se a quantidade de dinheiro é suficiente para satisfazer suas necessidades e se têm tempo para o lazer. Os professores foram perguntados ainda se estão satisfeito com as condições do local aonde mora, o acesso aos serviços de saúde e os meios de transporte. Este item foi avaliado com a menor média $69,7( \pm 0,8)$, embora ainda apontando para uma qualidade de vida boa.

Alguns aspectos chamam a atenção para a forma como o índice de qualidade de vida pode se relacionar com características específicas do trabalho de professor. A correlação de Pearson, realizada entre o tempo que o participante exerce a docência, é nula entre o tempo de serviço e o índice de qualidade de vida no domínio físico ( $\mathrm{r}$ $=0.0259 ; \mathrm{p}=0.7227$ ), entretanto encontrou-se correlação fraca, positiva, porém significativa entre o tempo de serviço e o índice de qualidade de vida para o domínio psicológico $(\mathrm{r}=0,1429$; $\mathrm{p}$ $=0,0498$ ), ou seja, quanto mais tempo de carreira de professor, maior será o índice de qualidade de vida em relação ao domínio psicológico.

O professor que atua há mais anos na profissão torna-se referência, encontra menor dificuldade para lidar com situações inesperadas em sala de aula, bem como se sente menos pressionado com as indagações dos alunos e constrói um vínculo forte com a instituição de ensino.

Em relação aos quesitos do escore ambiental e da carga horária, a correlação de Pearson aponta que esta relação é nula entre o tempo de serviço e o índice de qualidade de vida no domínio ambiental.

Quando relacionada às cargas horárias semanais e os índices de qualidade de vida à correlação de Pearson, encontramos correlação fraca, negativa e não significativa entre a carga horária semanal e o índice de qualidade de vida no domínio físico $(r=-0,1147, p=0,1167)$. Entretanto há correlação fraca, negativa e significativa entre a carga horária semanal e o índice de qualidade de vida no domínio psicológico $(\mathrm{r}=-0,1442, \mathrm{p}=$ $0,0484)$. Esta correlação demonstra que, na medida em que aumenta a carga horária semanal do professor, menor é sua qualidade de vida no domínio psicológico. Destaca-se que este escore é obtido pela percepção do professor frente a seus sentimentos sobre a aparência, o desespero, a ansiedade e a satisfação pessoal. Assim, os professores com carga horária extenuante sentemse menos realizados ou com menos tempo para pensarem em si, suas necessidades individuais e sua posição em relação à sua vida.

Este dado demonstra o quanto os professores primam pelo reconhecimento social inerente à sua profissão e advém do século XIX. Como pessoas que são referência para teorias complexas, para formar profissionais e para pensar no futuro da população, abrem mão de enxergarem-se e de buscarem momentos de prazer. O trabalho vai adquirindo a centralidade da vida destes profissionais.

O trabalho do professor envolve criar vínculos sociais, estimular a autonomia e a responsabilidade através de uma atividade teórico-prática, intelectual e administrativa. Sendo vista como uma profissão de extrema relevância social, entretanto, na contramão deste reconhecimento, o docente subestima suas necessidades de saúde e pode iniciar um processo de adoecimento ${ }^{14}$.

É neste contexto que as concepções de trabalho marxistas se configuram, já que ministrar aula pode tornar-se um processo automático ${ }^{15}$. 
Três itens são fundamentais nessa discussão: a necessidade e capacidade do trabalhador, a organização do trabalho e a tarefa desempenhada. O controle que o professor exerce sobre seu trabalho é realizado por suas características individuais, que determina a intensidade do esforço que será empregado durante a atividade. Em relação à organização do trabalho, o professor tem a liberdade de realizar as mudanças que julga necessárias no seu processo de trabalho, quando as atividades laborais restringem este tipo de alteração, principalmente por atividades centralizadoras que têm como objetivo a uniformidade da atividade. Por fim, o planejamento das atividades realizadas pelos professores permite o conhecimento sobre todo o processo de trabalho e, consequentemente, o trabalhador se reconhece na atividade desempenhada ${ }^{16}$.

A correlação aplicada entre a carga horária e o domínio social e o índice de qualidade de vida foi identificada como fraca, negativa e significativa $(r=-0,1649, p=0,0239)$. O dado destaca que quanto maior a carga horária menor o índice de qualidade de vida no domínio social que é obtido através das relações sociais com colegas, vida sexual e o apoio entre os colegas.

Assim percebe-se que com o tempo estas relações se tornam frágeis e o apoio necessário em diferentes momentos pode não ser o esperado. Estes laços são importantes para a construção de um apoio. O convívio social, como relata Durkheim (1858-1917) é fonte de solidariedade e de empatia entre os pares. A partir de momentos que o professor não se identifica como "igual", seja por falta de convívio ou por ser professor de determinada área que o diferencia, o convívio com o próximo pode ficar prejudicado.

O domínio ambiental também apresenta correlação fraca, negativa e significativa entre a carga horária semanal e o índice de qualidade de vida no domínio ambiental $(\mathrm{r}=-0,1494, \mathrm{p}=$ 0,0409 ). Os escores de qualidade de vida foram identificados a partir de fatores inerentes ao cotidiano como segurança, sobre o ambiente em relação à poluição, ao barulho entre outros, à quantidade de dinheiro e ao tempo para lazer.

A correlação mostra que quanto maior a carga horária menor o índice de qualidade de vida. Quanto mais os professores dedicam seu tempo ao trabalho menor o espaço para o lazer, maiores as preocupações em "chegar a tempo", em não se sentir parte do ambiente, em não pertencer ao meio.

Este dado pode ser demonstrado pelo relato do professor 02 , quando perguntado sobre lazer, aponta que possui poucos momentos, pois, nas suas palavras, em "[...] muitos sábados dou aula [...]", ou ainda pelo professor 161 que afirma não ter tempo para lazer, pois "trabalha [...] manhã, tarde e noite”. Destaca-se que os professores, em função de ministrarem disciplinas em fins-de-semana, orientar trabalhos de conclusão de curso, preparar aula e corrigir materiais, desprendem do tempo de convívio social ou de realizarem atividade de seu interesse particular para permanecerem realizando atividades inerentes ao trabalho. Esta necessidade de atenção constante pode ser o responsável por gerar frustrações e cansaço ou fadiga aos professores.

O dinheiro é um caso à parte, pois os professores de graduação tendem a ter uma boa renda, conforme se observa na fala do Professor 58:

ter mais tempo livre, meu trabalho é muito bom, mas quase não sobra tempo nos dias de semana e nem nos finais de semana (Por favor me ajude). Qualidade de vida também é poder viajar, ir ao cinema, tocar instrumento musical. Dinheiro eu tenho bastante, mas não tenho tempo disponível para lazer. Estou procurando concurso para alguma instituição federal onde a carga de trabalho é menor. Também estou procurando concurso fora da área docente, em algum órgão público burocrático, onde se sai do trabalho às 18 h e não se leva trabalho para casa nem de noite nem no final de semana (Professor 58).

O pedido de ajuda traz a necessidade de encontrar-se como um ser além do trabalho, os sentimentos que nos levam a repensar a prática e até mesmo a atuação no trabalho. É evidente que a busca por apoio, repensar as necessidades, limitar as cargas de trabalho é fundamental para pensar-se a qualidade de vida.

O fator idade e o índice de qualidade de vida no domínio psicológico também apresenta correlação fraca, positiva e significativa $(r=0,1885$, $\mathrm{p}=0,0095$ ), indicando que, quanto maior a idade, maior o índice de qualidade de vida no domínio psicológico. Este dado demonstra o quanto docentes atuantes há mais tempo sentem maior segurança, lidam melhor com as diversidades, compreender melhor o posicionamento de colegas, alunos e chefia, bem como suas expectativas são outras.

Há correlação fraca, positiva e não significativa entre a idade e o índice de qualidade de vida no domínio físico $(\mathrm{r}=0,1338, \mathrm{p}=0,0664)$ e domínio ambiental $(\mathrm{r}=0,1203, \mathrm{p}=0,0994)$. No domínio social, a correlação é nula entre a idade e o índice de qualidade de vida no domínio social.

$\mathrm{O}$ teste $\mathrm{t}$ foi aplicado entre os escores de qua- 
lidade de vida na comparação entre os professores que referem ter realizado processo seletivo ou não. Não se identificou significância nos escores de qualidade de vida.

No que tange a titulação e os escores apontados nos domínios de qualidade de vida, não houve diferenças significativas nos escores de qualidade de vida e na titulação entre especialistas e mestres e entre mestres e doutores $(\mathrm{H}=6,92, \mathrm{p}=$ 0,074). Entretanto a análise através da ANOVA para dois critérios (titulação e domínios de qualidade de vida), seguida do teste de Tukey, aponta que há diferenças significativas nos escores de qualidade de vida de especialistas e doutores $(\mathrm{p}<$ $0,05)$ bem como há diferenças entre os escores, segundo a titulação, nos domínios físico e ambiental $(\mathrm{p}<0,01)$ e psicológico e ambiental $(\mathrm{p}<$ 0,05 ), como pode ser visualizado no Gráfico 2.

A diferença entre os escores de professores especialistas e doutores justifica-se pelo fato de que professores doutores, na maioria das vezes, possuem vínculos de trabalho sólidos, com cargas horárias mais estáveis e planos de trabalho determinados. O dado corrobora com a correlação feita entre carga horária e qualidade de vida. $\mathrm{Na}$ análise do gráfico é possível perceber que os escores de qualidade de vida dos docentes com titulação de especialista permanecem entre 69 a 72 (média 70,5 $\pm 0,87$ ) nos diferentes domínios, enquanto para docentes doutores os escores foram mais altos, variando entre 71 a 75 (média 73,5 \pm 0,87) nos diferentes domínios e os mestres tiveram uma variação entre 69 e 75 (média 71,8 \pm 1,25). A média do escore de qualidade vida, considerando todas as titulações, foi no domínio físico $(74,0 \pm 1,00)$ e menor no domínio ambiental $(69,7 \pm 0,67)$.

Professores especialistas ou que estejam iniciando na carreira de docente tendem a aceitar maiores cargas horárias, bem como, sentem-se mais pressionados e inseguros, já que ainda estão se inserindo no mercado de trabalho.

Quando feita esta mesma análise para o tipo de vínculo empregatício e os escores apontados nos domínios de qualidade de vida, também não houve diferenças significativas nos escores de qualidade de vida e o tipo de vínculo empregatício (horistas, tempo parcial e tempo integral) $(\mathrm{H}=$ $5,40, \mathrm{p}=0,144)$. Entretanto a análise através da ANOVA dois critérios (vínculo e domínios de qualidade de vida), seguida do teste de Tukey, aponta que há diferenças significativas nos escores de qualidade de vida de professores com tempo parcial e tempo integral $(\mathrm{p}<0,05)$ bem como há diferença entre os escores, segundo o tipo de vínculo, nos domínios físico e ambiental $(\mathrm{p}<0,05)$, conforme pode ser visualizado no Gráfico 3 .

A análise deste gráfico permite verificar que a média de qualidade de vida (em todos os domínios) é maior entre os professores com tempo integral $(71,0 \pm 1,73)$, e maior entre os professores com dedicação parcial $(75,0 \pm 1,08)$, tendo os horistas uma média intermediária $(73,5 \pm 0,65)$. O que chama a atenção é que, em todos os tipos de vínculo empregatício, novamente a média de escore de qualidade de vida no domínio ambiental é o menor $(70,33 \pm 0,88)$

O fato de que professores que realizam atividades profissionais além da docência pode ser

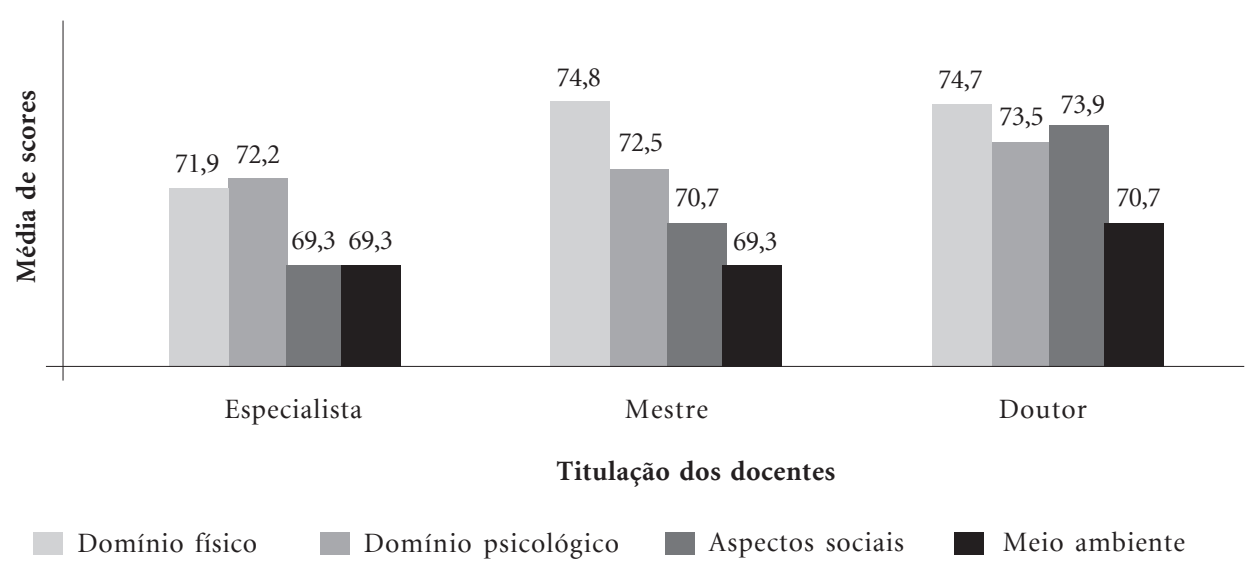

Gráfico 2. Média dos escores de qualidade de vida conforme titulação segundo os domínios do questionário de qualidade de vida Whoqol-bref. 


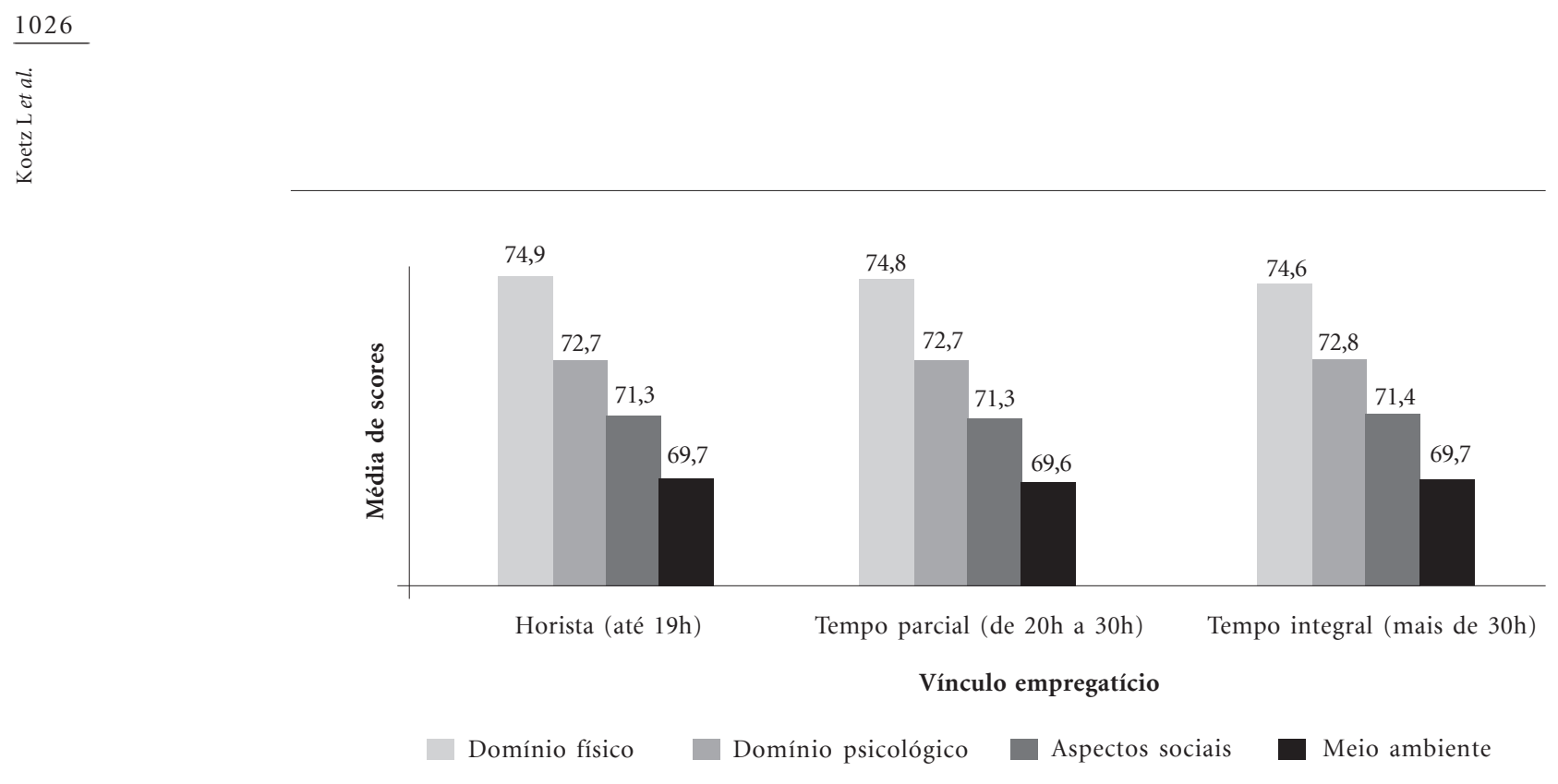

Gráfico 3. Média dos escores de qualidade de vida conforme vínculo empregatício segundo os domínios do questionário de qualidade de vida Whoqol-bref.

explicada em função de que os ambientes de trabalho irão variar, assim as sensação de rotinas presentes no trabalho são minimizadas.

Os resultados demonstram que apesar das médias de escore de qualidade de vida nos domínios físicos, social, psicológicos e ambiental ser consideradas boas, alguns aspectos demonstram a necessidade de se refletir sobre a atuação do professor, ou melhor, do cidadão/ser humano.

O teste estatístico ANOVA, através da prova de Tukey, aponta que há diferença significativa nos escores de qualidade de vida no domínio ambiental de professores que exercem atividade externa à docência $(\mathrm{p}=0,0431)$, apontando que, professores que exercem atividade extra às de ensino possuem uma melhor qualidade de vida nos aspectos relacionados ao ambiente do que professores que não possuem atividade extra.

A carga horária dos professores é intensa e demanda grandes períodos de preparo das disciplinas. Este ponto deve ser discutido e repensado, pois há que se remanejar os horários e se definir os limites entre trabalho e vida. Diferentes professores apontam esta necessidade.

Segundo Pagnez ${ }^{12}$, professores que estão iniciando suas atividades são aprendizes acerca da cultura da instituição e de sua organização, neste período os professores aprendem mecanismos de atuação pedagógica e da instituição de ensino. Após o terceiro ano, segundo a autora, o professor passa por um momento de desenvolvimento profissional, um processo pelo qual articula teoria e prática para aperfeiçoamento dos domínios intelectuais, institucional, pessoal, pedagógico e social.

Os dados coletados apontam que as médias dos escores de qualidade de vida nos domínios físico, psicológico, social e ambiental são consideradas boas, sendo o ambiental, em todas as análises, o apontado com a menor média. Apenas 1\% dos professores questionados tiveram um escore de qualidade de vida enquadrado como ruim. Para 19\% o escore indica que a qualidade vida não é nem ruim nem boa e a maioria apresenta escores de qualidade vida bom (49\%) e muito bom $(30 \%)$. Entretanto, ao correlacionar os dados se percebe a necessidade de se pensar sobre aspectos da qualidade de vida dos docentes.

Os escores de qualidade de vida no domínio psicológico de professores especialistas são menores em relação aos professores doutores. Ressaltando a necessidade de se realizar espaços para discutir a vida profissional do docente. As diferenças entre estes professores devem-se ao fato de que os especialistas nem sempre possuem vínculos de trabalho estáveis, enquanto os doutores possuem vínculos consolidados e determinados de atuação.

Destaca-se que apesar da maior parte dos professores ter indicado uma qualidade de vida boa, cerca de $20 \%$ destes profissionais apontaram não possuírem uma boa qualidade de vida, apesar da boa remuneração e do trabalho em instituições de ensino ser um ambiente que estimule o processo ensino/aprendizagem constantemente. 
Neste sentido, é necessário pensar em espaços de apoio aos docentes, onde possam expor suas ansiedades e dúvidas. Importante é que estes espaços não tenham como caráter "descobrir dificuldades", mas sim um espaço de apoio onde um professor possa auxiliar o outro em suas dificuldades, construindo e desconstruindo as dificuldades e as potencialidades de ser professor.

Percebe-se que o trabalho toma uma dimensão fundamental para os professores. Por tratar-se de uma profissão em que a cultura e o reconhecimento social são preponderantes, ainda mais no que tange ao ensino superior, ações de educação em saúde serão de extrema importância para pensar a qualidade de vida.

Por fim, é relevante destacar a imensa responsabilidade de um professor ao assumir o papel de protagonista na formação de futuros profissionais brasileiros, bem como em nos permitir conhecê-los como atores da educação. Fica a admiração por escolherem o desafio de serem educadores num momento aonde as tecnologias permitem um fluxo tão intenso de comunicação que exige constante formação.

\section{Colaboradores}

L Koetz, C Rempel e E Périco participaram igualmente de todas as etapas de elaboração do artigo. 


\section{Referências}

1. Brasil. Câmara dos Deputados. Projeto de Lei 7639/ 10. Dispõe sobre a definição, qualificação, prerrogativas e finalidades das Instituições Comunitárias de Educação Superior - ICES, disciplina o Termo de Parceria e dá outras providências. [acessado 2013 mar 17]. Disponível em: http://www.camara.gov.br/ proposicoesWeb/prop_mostrarintegra;jsessionid $=235$ FB64E88761889307B789BCE1E3B8E.node2?cod teor $=789188 \&$ filename $=\mathrm{PL}+7639 / 2010$

2. Costa LC. A universidade brasileira e a excelência internacional. Associação Brasileira das Universidades Comunitárias (ABRUC). [página na Internet]. [acessado 2011 abr 7]. Disponível em: http:// www.abruc.org.br/003/00301009.asp?ttCD_CHAVE $=137989$

3. World Health Organization (WHO). Quality of life. [página da Internet]. [acessado 2011 abr 8]. Disponível em: http://www.who.int/en/

4. Fleck MPA. Versão em Português dos instrumentos de avaliação de qualidade de vida (WHOQOL). Porto Alegre: UFRGS, Departamento de Psiquiatria; 1998.

5. Brasil. Ministério da Saúde (MS). Lei 8080, de 19 de Setembro de 1990. Dispõe sobre as condições para a promoção, proteção e recuperação da saúde, a organização e o funcionamento dos serviços correspondentes e dá outras providências. Diário Oficial da União 1990; 20 set.

6. Ayres M, Ayres Júnior M, Ayres DL, Santos AAS. Bioestat - Aplicações Estatísticas nas Áreas das Ciências Biomédicas. 5a Edição. Belém: Mamirauá; 2007.

7. Bardin L. Análise de Conteúdo. Lisboa: Edições 70; 2004.

8. Padrão MB. Avaliação da qualidade de vida de doadores vivos após o transplante renal utilizando os instrumentos SF-36 e WHOQOL-bref. 2008 [dissertação]. São Paulo: Faculdade de Ciências Médicas; 2008.

9. Malhotra NK. Pesquisa de marketing: uma orientação aplicada. 4a Edição. Porto Alegre: Bookman; 2006.
10. Campos WCR, Ito AM. Condições de Trabalho e Saúde dos Trabalhadores do Ensino Privado no Estado do Rio Grande do Sul. São Paulo: FeteeSul; 2009. (Informe de caráter técnico-executivo)

11. Belluci NP. Estranhamento; Alienação e Discriminação de Gênero: O Trabalho Da Mulher Professora. In: V Encontro Brasileiro de Educação e Marxismo. Anais UFSC, Florianópolis, Santa Catarina, 2011. [acessado 2011 set 11]. Disponível em: http://www. 5ebem.ufsc.br/trabalhos/eixo_03/e03f_t003.pdf

12. Pagnez KSMM. A identidade profissional docente: um olhar interdisciplinar. In: Bassit AZ, organizador. O interdisciplinar: olhares contemporâneos. São Paulo: Factasch Editora; 2010. p.165-180.

13. Maar WL. A dialética da centralidade do trabalho. Cienc. Cult. 2006; 58(4):26-28.

14. Bicudo-Pereira IMT, Penteado RZ, Bydlowski CR, Domênico MR, Grazzeli ME. Escolas Promotoras de Saúde: onde está o trabalhador professor? Saúde em Revista 2003; 5(11):29-34

15. Landini SR. Professores, trabalho e saúde: as políticas educacionais, a materialidade histórica e as consequências para a saúde do trabalhador-professor. Colloquium Humanarum 2007; 4(1):8-21.

16. Sorato L, Olivier-Heckler C. Os trabalhadores e seu trabalho. In: Codo W, organizador. Educação: carinho e trabalho. Petrópolis: Vozes; 1999. p. 89-110.

Artigo apresentado em 03/01/2011

Aprovado em 09/01/2011

Versão final apresentada em 11/01/2011 